\title{
Influence on Jet Performance of Non pressure-accumulated and Handheld Fire Extinguishing Bomb
}

\author{
Xin Liu ${ }^{1, a^{*}}$, Hongwei Zhuang ${ }^{1, b}$, Pengfei $\mathrm{Yu}^{1, \mathrm{c}}$ and Wenhao Yang ${ }^{2, \mathrm{~d}}$ \\ ${ }^{1}$ Equipment Engineering College, Engineering University of CAPF Shaanxi Xi'an 710086, China \\ ${ }^{2}$ Department of Information Engineering, Engineering University of CAPF Shaanxi Xi'an 710086, \\ China \\ a15291182317@163.com, bzhuanghw01@163.com, '413249654@qq.com, 'dywh0819@yeah.net
}

Keywords: Handheld fire extinguishing bomb; The best jet distance; The largest strewn area; Orthogonal test

\begin{abstract}
Aimed at the design of non pressure-accumulated and handheld fire extinguishing bomb, the rules of the influence of structure on jet performance were studied by the method of equivalent diameter and distance. The factors such as diameter of the burning area of gas-generating agents, length-to-diameter ratio of cartridge, internal taper of sealing cap, and nozzle diameter were analyzed employing single factor tests on the influence rules for the best jet distance and the largest strewn area, then the orthogonal tests were carried out within a safety index, which is, the jet distance is greater than $2.4 \mathrm{~m}$. Results show that under the optimum structure combination where the diameter of burning area is $18 \mathrm{~mm}$, length-to-diameter ratio $160 \mathrm{~mm} / 50 \mathrm{~mm}$, internal taper $130^{\circ}$, and nozzle diameter $7 \mathrm{~mm}$, the largest strewn area is $1.30 \mathrm{~m}^{2}$.
\end{abstract}

\section{Introduction}

Recent years have seen in-depth applications of aerosol fire extinguishing technology ${ }^{[1-2]}$ and non-stored pressure fire extinguisher technology (solid-gas conversion and gas drive technology ${ }^{[3-8]}$, which have broken the traditional fire extinguishing device using an inert gas reservoir pressure brought low security impact, large size and other unfavorable factors, and make the modern fire-fighting equipment become miniaturized, portable and handheld.

The drive technology of non pressure-accumulated and handheld fire extinguishing bomb is the use of gas designed with a hand-held security firm, for quick start operation and being hot and cold composite and efficient fire extinguishing aerosol. In the projectile body structure, the gas pressure produced by gas-generating agents is the entire extinguishing bomb of the power source; the combustion area (it means "burning surface diameter" here) controls the gas production rate; ratio of length to diameter of cartridge controls ultra-fine powder injection the role and function of the distance area, internal taper of sealing cap gives ultra-fine powder injection the direction, angle and initial velocity; nozzle diameter controls the flow of ultra-fine powder and these four factors have a significant impact on the ejection performance. The best jet distance and the largest strewn area are reflected in two key indicators of ejection performance.

By spraying performance tests, the jet set at a distance of $2.4 \mathrm{~m}$ safety indicators (to ensure operator safety). Studying these four factors on the best jet distance and the largest strewn area and determining the best structure combination can provide a basis for further optimization test airframe structure and improve injection performance.

\section{Ejection Performance Test}

Overall Structure. Non pressure-accumulated and handheld fire extinguishing bomb is mainly made up of the projectile body and the handle. The overall structure is shown in Fig. 1. 


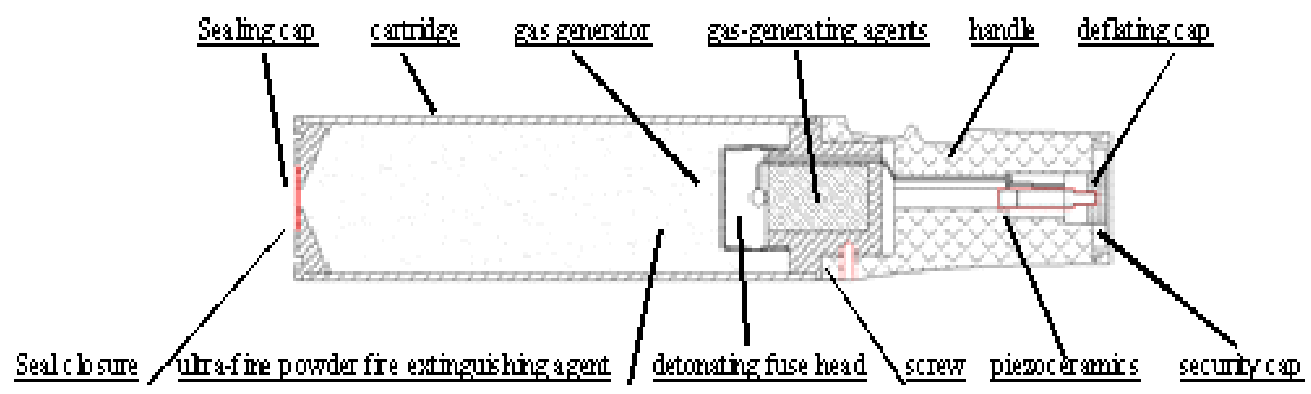

Figure 1. The overall structure of non pressure-accumulated and handheld fire extinguishing bomb

Its principle is: poke the insurance cover and press the switch cap so that the piezoelectric ceramic starts, ignition firing head, ignition gas-generating agents, by burning chemical reaction to produce pyrotechnic aerosol with a certain pressure, breaks the seal film, the bulk in the interior of a smooth elastomer ultra-fine powder, sustained, quickly ejected, acting on a fire burning object surface.

Sealing cap is screwed to the cartridge (thickness $2 \mathrm{~mm}$ ), as is shown in the cartridge and the sealing cap structure is shown in Fig 2 and Fig. 3.

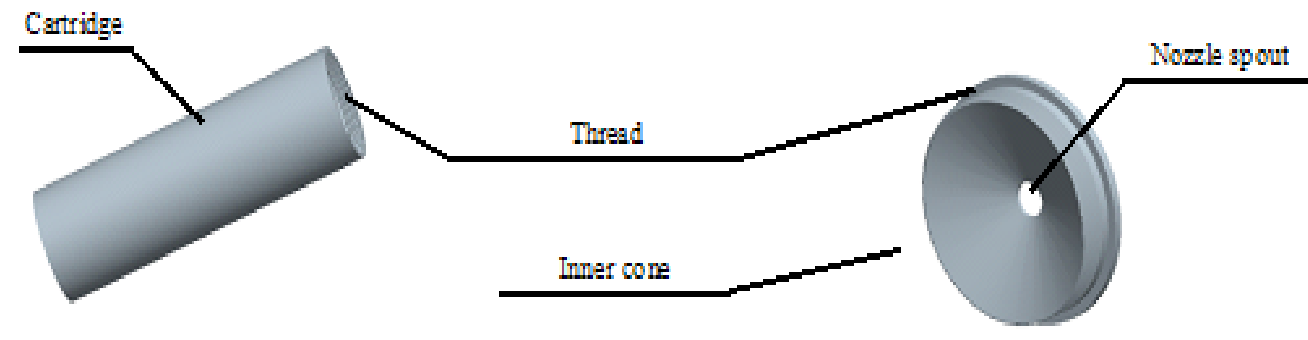

Figure 2. Cartridge

Figure 3. Sealed cover

Materials and Equipment. Gas-generating agents; ultra-fine powder fire extinguishing agent; fire extinguishing bombs; tape; 1.5m high flag pole; high-speed camera, Miro3, US VRI companies.

Assay Method. Measurement model is as follows:

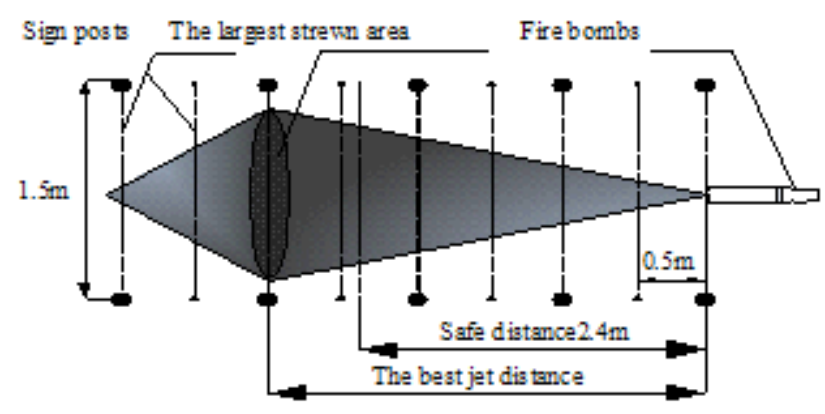

Figure 4. Injection performance testing schematic

(1) Mark the distance and start fire extinguishing bomb. On level ground mark the location of the fire extinguishing bomb injection every 0.5 meters with a flag pole marking the distance in the direction of injection, while giving signs with a red safety distance of $2.4 \mathrm{~m}$; start fire extinguishing bomb shot with high-speed cameras.

(2) Equivalent diameter and the distance [9]. The extinguishing agent is injected to spread 
maximum disc height which converted to an equivalent area of a circle of diameter $\mathrm{d}$, then use $\mathrm{S}=\pi \mathrm{d}^{2} / 4$ to calculate the largest strewn area $\mathrm{S}$; and by an equivalent distance calculate the best jet distance L.

Test Details. Select 5 Groups pressure medicine whose density is $1.5 \mathrm{~g} / \mathrm{cm}^{3}$, height $20 \mathrm{~mm}$, the combustion surface of different diameter gas-generating agents $(14 \mathrm{~mm}, 16 \mathrm{~mm}, 18 \mathrm{~mm}, 20 \mathrm{~mm}$, $22 \mathrm{~mm})$; select 5 groups of cartridges with different aspect ratio $(140 \mathrm{~mm} / 54 \mathrm{~mm}, 150 \mathrm{~mm} / 52 \mathrm{~mm}$, $160 \mathrm{~mm} / 50 \mathrm{~mm}, 170 \mathrm{~mm} / 48 \mathrm{~mm}, 150 \mathrm{~mm} / 46 \mathrm{~mm}$ ); select within five groups taper appropriate sealing caps $\left(100^{\circ}, 110^{\circ}, 120^{\circ}, 130^{\circ}, 140^{\circ}\right)$; choose 5 groups of different diameter orifices $(5 \mathrm{~mm}$, $6 \mathrm{~mm}, 7 \mathrm{~mm}, 8 \mathrm{~mm}, 9 \mathrm{~mm}$ ), study the single factor which affects the best jet distance and the largest strewn area in order to gain influence laws of various factors, and select the best jet distance which is greater than $2.4 \mathrm{~m}$, the larger maximum strewn area horizontal. Then spread the largest area of investigation index and orthogonal table $\mathrm{L}_{9}\left(3^{4}\right)$ design of pilot programs by some sort of poor law factors and the best combination of structure.

\section{Results and Discussion}

Effect of the Largest Strewn Area to the Diameter of Burning Area of Gas-Generating Agents. Diameters of burning area of gas-generating agents are $14 \mathrm{~mm}, 16 \mathrm{~mm}, 18 \mathrm{~mm}, 20 \mathrm{~mm}$, and $22 \mathrm{~mm}$. We take the middle value of the remaining factor level, that is, length-to-diameter ratio of cartridge is $160 \mathrm{~mm} / 50 \mathrm{~mm}$, internal taper of sealing cap $120^{\circ}$, nozzle diameter $7 \mathrm{~mm}$, we get the best jet distance and the largest strewn area of grain burning surface diameter variation, as is shown in Fig. 5 .

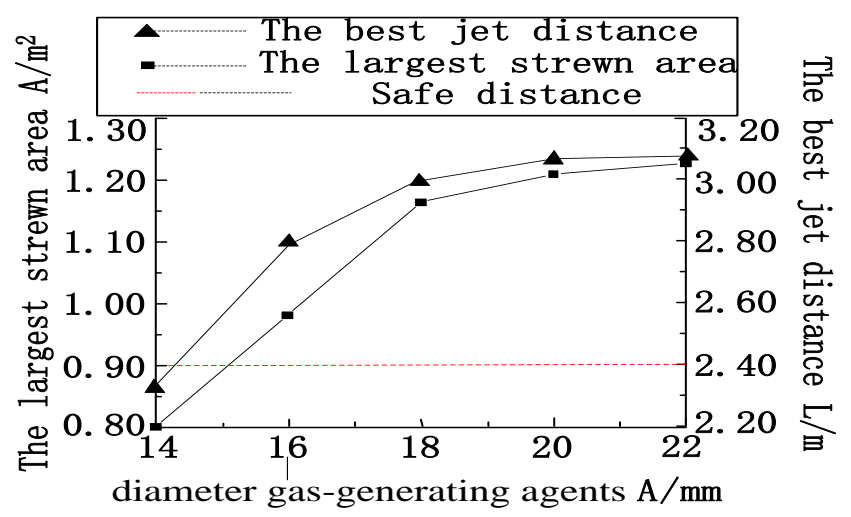

Figure 5. Effect of combustion surface diameter of ejection performance

Fig. 5 shows that, with the increase of the diameter of burning area of gas-generating agents, the best jet distance and the largest strewn area gradually increase; when the diameter goes to $18 \mathrm{~m} 2$, the leveling is off. This is mainly due to the fact that when ignition starts, grain is an end combustion, the greater the combustion surface, the faster the gas production rate; the greater the gas pressure, the better the particle ejection stability; therefore, the greater the distance, and the more the ejection to the largest strewn area of the ultra-fine powder spread, the larger the area; however, 90 percent of the size of ultra-fine powder particle is $20 \mu \mathrm{m}$ or less (smaller particles), and its kinetic energy decreases rapidly with the combustion surface and gas continues, particle injection rate changed little, the ultra-fine powder which injected to the largest spray area increased little, spray distance and spread area increased little.

Effect of length-to-diameter ratio of cartridge on the largest strewn area. Ratio of length to diameter of cartridge are $140 \mathrm{~mm} / 54 \mathrm{~mm}, 150 \mathrm{~mm} / 52 \mathrm{~mm}, 160 \mathrm{~mm} / 50 \mathrm{~mm}, 170 \mathrm{~mm} / 48 \mathrm{~mm}$, $180 \mathrm{~mm} / 46 \mathrm{~mm}$. We take the middle value of the remaining factor level, that is, diameter of burning area of gas-generating agents is $20 \mathrm{~mm}$, internal taper of sealing cap $120^{\circ}$, nozzle diameter $7 \mathrm{~mm}$ to give the best jet distance and the largest strewn area with the variation of ratio of length to diameter of cartridge, as shown in Fig. 6. 


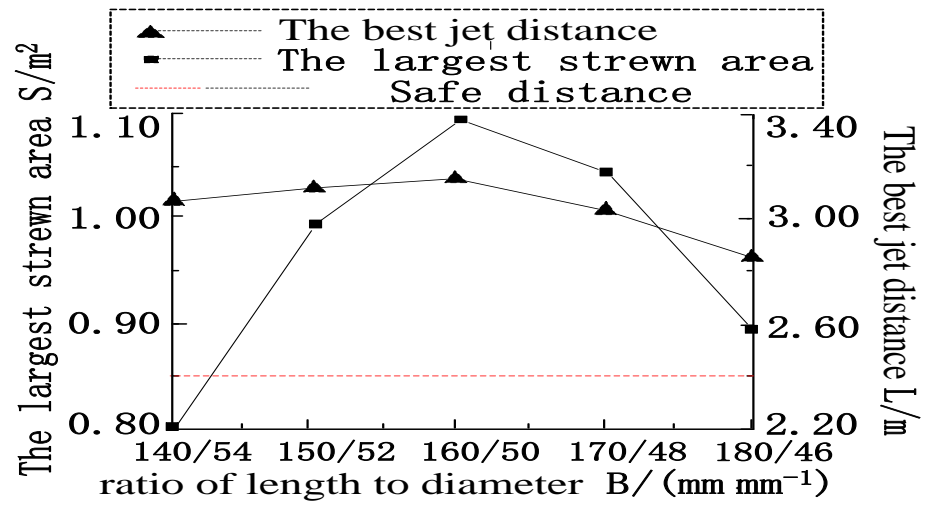

Figure 6. Effect in the ratio of length to diameter to the ejection performance

Fig. 6 shows that with the increase of the ratio of length to diameter of cartridge, the best jet distance gradually becomes closer, and the largest strewn area changes from increasing first and then decreasing. This is mainly because the ratio of length to diameter of cartridge controls gas thrust of the role and function of the distance area, thus affecting the jet effect. The total momentum of gas thrust is constant. As the aspect ratio increases, the role of area decreases, thus individual particles $\mathrm{m}$ share of the momentum $\mathrm{P}$ increases. According to $\mathrm{P}=\mathrm{mv}$, jet velocity $\mathrm{v}$ increases, the spray distance becomes far and more ultra-fine powder spray to the largest strewn area, causing the increase of spread areas; as the aspect ratio continues to increase, the ejection velocity of particles changes little, but the role of distance increases, causing increasing energy loss and resulting in the ejection distance being closer while jet spread area smaller.

Effect of Internal Taper of Sealing Cap on the Largest Strewn Area. Internal taper of sealing cap is $100^{\circ}, 110^{\circ}, 120^{\circ}, 130^{\circ}$, and $140^{\circ}$ respectively. We take the middle value of the remaining factor level, that is, diameter of burning area of gas-generating agents is $20 \mathrm{~mm}$, ratio of length to diameter of cartridge $160 \mathrm{~mm} / 50 \mathrm{~mm}$, nozzle diameter $7 \mathrm{~mm}$, then we get the best jet distance and the largest strewn area cover variation sealed within the taper, shown in Fig 7.

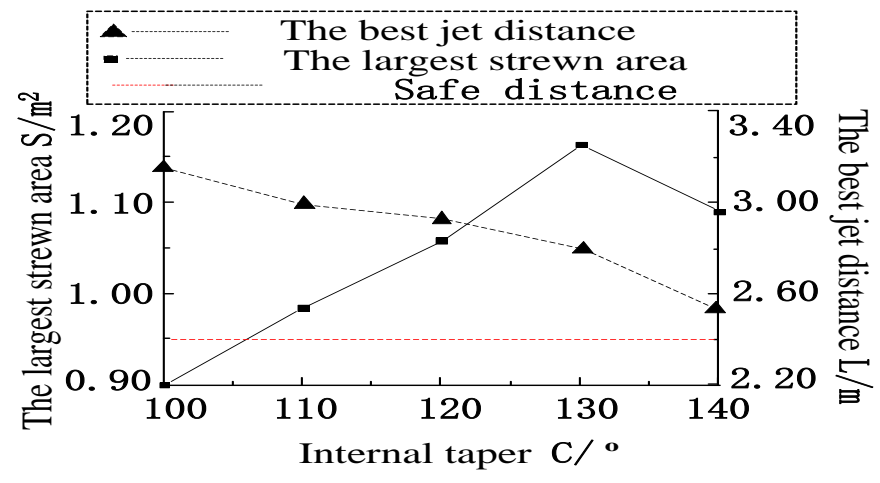

Figure 7. Influence on the ejection performance taper

Fig. 7 shows that with the increase in internal taper of sealing cap, the best jet distance near the injection area shows that the largest strewn area increases then decreases changes. This is mainly because the internal taper imparts ejection direction of ultra-fine powder, spread angle and initial velocity, thus affecting the ejector effect. When the inner taper increases, ultra-fine powder is ejected from the nozzle through the inner cone, divergence angle increases slightly, and the largest strewn area increases. However, it will reduce the initial velocity, causing worse directionality, and spray distance becomes closer; if inner taper is too large, the particles within the cone is difficult to impart good early speed, then spread angle decreases.

Effect of Nozzle Diameter on the Largest Strewn Area. Nozzle diameter being $5 \mathrm{~mm}, 6 \mathrm{~mm}$, $7 \mathrm{~mm}, 8 \mathrm{~mm}$, and $9 \mathrm{~mm}$, we take the middle value of the remaining factor level, that is, diameter of 
burning area of gas-generating agents is $20 \mathrm{~mm}$, ratio of length to diameter of cartridge $160 \mathrm{~mm} /$ $50 \mathrm{~mm}$, internal taper of sealing cap $120^{\circ}$, we get the best jet distance, the largest strewn area orifice with a diameter variation, shown in Fig. 8.

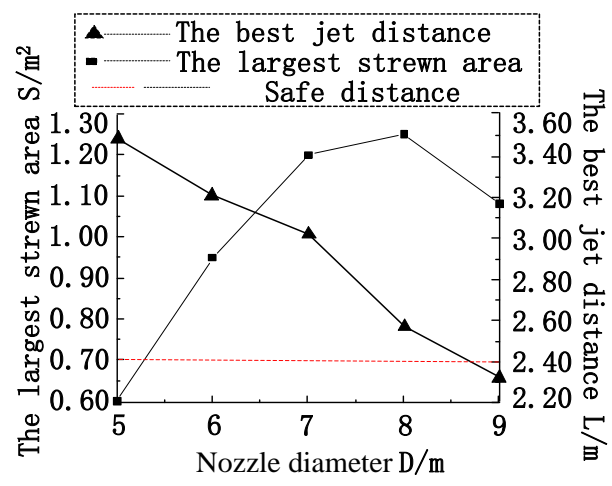

Figure 8. Effect of spout diameter of ejection performance

Fig. 8 shows that with the increase of the diameter of the orifice, the best jet distance gradually becomes closer, and the largest strewn area shows that a slow change firstly increases and then decreases. This is mainly because of the flow rate and flow control of nozzle diameter particle injection. With the increase of the diameter of the injection flow rate, the particles are injected to increase the maximum area of the spread, the spread area increases, but the individual particle's export movement speed is corresponding slow, and the best jet distance gradually becomes closer; as the diameter continues to increase, although traffic continues to increase, the particles, due to the slow speed, will be more dispersed, then the largest strewn area decreases.

Orthogonal Test. 4 single factors in selecting the best of each jet distance are greater than $2.4 \mathrm{~m}$, the largest strewn area has got three levels, namely diameter of burning area of gas-generating agents select as $18 \mathrm{~mm}, 20 \mathrm{~mm}, 22 \mathrm{~mm}$, ratio of length to diameter of cartridge $150 \mathrm{~mm} / 52 \mathrm{~mm}$, $160 \mathrm{~mm} / 50 \mathrm{~mm}, 170 \mathrm{~mm} / 48 \mathrm{~mm}$, internal taper of sealing cap $120^{\circ}, 130^{\circ}, 140^{\circ}$, nozzle diameter $6 \mathrm{~mm}, 7 \mathrm{~mm}, 8 \mathrm{~mm}$. Orthogonal experiment [9-10] (Table 1).

Table 1 Orthogonal contrast test results

\begin{tabular}{|c|c|c|c|c|c|c|}
\hline \multirow[b]{2}{*}{ Test } & \multicolumn{4}{|l|}{ Factor } & \multicolumn{2}{|l|}{ Result } \\
\hline & $\begin{array}{l}\text { Diameter of } \\
\text { burning area of } \\
\text { gas-generating } \\
\text { agents } \\
\text { A / mm }\end{array}$ & $\begin{array}{lr}\text { Ratio } & \text { of } \\
\text { length } & \text { to } \\
\text { diameter } & \mathrm{B} \\
/ \quad(\mathrm{mm} & \bullet \\
\left.\mathrm{mm}^{-1}\right) & \end{array}$ & $\begin{array}{l}\text { Internal } \\
\text { taper } \mathrm{C} /{ }^{\circ}\end{array}$ & $\begin{array}{l}\text { Nozzle } \\
\text { diameter } \\
\mathrm{D} / \mathrm{mm}\end{array}$ & $\begin{array}{l}\text { The best } \\
\text { jet } \\
\text { distance } \\
\mathrm{L} / \mathrm{m}\end{array}$ & $\begin{array}{l}\text { The } \\
\text { largest } \\
\text { strewn } \\
\text { area S / } \\
\mathrm{m}^{2}\end{array}$ \\
\hline 1 & $18(1)$ & $150 / 52(1)$ & $120^{\circ}(1)$ & $6(1)$ & 3.2 & 0.90 \\
\hline 2 & $18(1)$ & $160 / 50(2)$ & $130^{\circ}(2)$ & $7(2)$ & 2.8 & 1.30 \\
\hline 3 & $18(1)$ & $170 / 48(3)$ & $140^{\circ}(3)$ & $8(3)$ & 2.5 & 1.15 \\
\hline 4 & $20(2)$ & $150 / 52(1)$ & $130^{\circ}(2)$ & $8(3)$ & 3.0 & 1.20 \\
\hline 5 & $20(2)$ & $160 / 50(2)$ & $140^{\circ}(3)$ & $6(1)$ & 2.5 & 0.95 \\
\hline 6 & $20(2)$ & $170 / 48(3)$ & $120^{\circ}(1)$ & $7(2)$ & 2.8 & 1.25 \\
\hline 7 & $22(3)$ & $150 / 52(1)$ & $140^{\circ}(3)$ & $7(2)$ & 2.6 & 1.15 \\
\hline 8 & $22(3)$ & $160 / 50(2)$ & $120^{\circ}(1)$ & $8(3)$ & 3.1 & 1.10 \\
\hline 9 & $22(3)$ & $170 / 48(3)$ & $130^{\circ}(2)$ & $6(1)$ & 3.1 & 0.80 \\
\hline$K_{1}$ & 1.117 & 1.083 & 1.117 & 0.883 & & - \\
\hline$K_{2}$ & 1.133 & 1.117 & 1.100 & 1.233 & & - \\
\hline$K_{3}$ & 1.017 & 1.067 & 1.083 & 1.150 & & - \\
\hline$R$ & 0.116 & 0.050 & 0.034 & 0.267 & & - \\
\hline
\end{tabular}


9 groups of test ejector effect shown in Fig. 9:
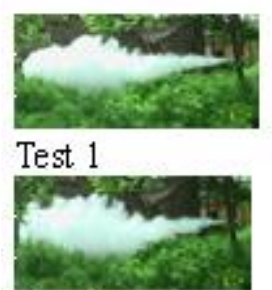

Test 4

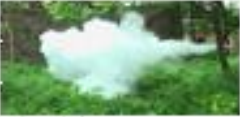

Test 7

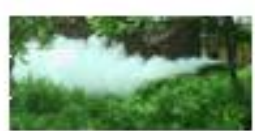

Test 2

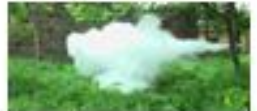

Test 5

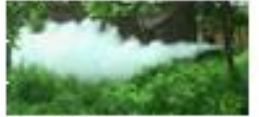

Test 8

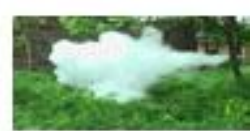

Test 3

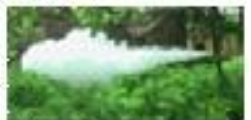

Test 6

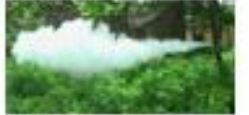

Test 9

Figure 9. Jet effect

Table comparable discovery: All spray test results, the best jet distance greater than $2.4 \mathrm{~m}$ safety indicators. Through the various levels of the average $\mathrm{K}$ factor and range $\mathrm{R}$, we obtaine the greatest impact of the largest strewn area: nozzle diameter > diameter of burning area of gas-generating agents > ratio of length to diameter of cartridge > internal taper of sealing cap. Orthogonal test, the best combination is as follows: diameter of burning area of gas-generating agents $18 \mathrm{~mm}$, ratio of length to diameter of cartridge $160 \mathrm{~mm} / 50 \mathrm{~mm}$, internal taper of sealing cap $130^{\circ}$, nozzle diameter $7 \mathrm{~mm}$, and its largest strewn area is $1.30 \mathrm{~m}^{2}$.

\section{Conclusions}

Through single factor test, when the ratio of length to diameter of cartridge is less than $150 \mathrm{~mm} /$ $52 \mathrm{~mm}$ or more than $8 \mathrm{~mm}$, we get the optimum injection short distance and poor security orifice diameter.

In the preferred situation that the best jet distance is greater than $2.4 \mathrm{~m}$ which meet the safety indicators, the factor that affects the largest strewn area is in the order of: nozzle diameter > diameter of burning area of gas-generating agents > ratio of length to diameter of cartridge > internal taper of sealing cap.

With orthogonal experiment, we get the best elastomeric structure: diameter of burning area of gas-generating agents is $18 \mathrm{~mm}$, ratio of length to diameter $160 \mathrm{~mm} / 50 \mathrm{~mm}$, internal taper of sealing cap $130^{\circ}$, nozzle diameter of $7 \mathrm{~mm}$, and then the largest strewn area is $1.30 \mathrm{~m} 2$.

\section{References}

[1] Guo Hong-bao, Yue Da-ke, et al. Aerosol fire extinguishing technology [M]. Beijing: Chemical Industry Press, 2005.

[2] K. Kwon,Y. Kim. Extinction effectiveness of pyrogenic condensed-aerosols extinguishing system [J]. Korean Journal of Chemical Engineering, 2013, 30(12):2254-2258.

[3] Li Xi-min, Xie Jiu-wei, et al. Modification of a non pressure-accumulated powder fire equipment [J]. Fire Science and Technology, 2010, 29(9): 790-793.

[4] Chen Yi-zong. Study on dynamic device of gas drive type dry powder fire extinction equipment [J]. Fire Science and Technology, 2013, 32(9): 1001-1003.

[5] Yao Jun-na. Application of portable pyrosol fire extinguisher to family cars [J]. Applied Science and Technology [J]. 2013, 40(6):80-82.

[6] Jiang Xiao-nan, Zhu Chen-guang, Lin Hong-xue, et al. Cooling and filter layer of aerosol fire extinguishing agent $[\mathrm{J}]$. Fire Science and Technology, 2013, 32(6): 652-655. 
[7] Du Li-qiang, Chai Tao. Approach on the Ultra-fine-powder Fire Extinguishing Technology [J]. Mechanical Management and Developmen, 2008, 23(3):94-95.

[8] Yin Zhi-ping, Zhu Qiong, et al. Study on Dispersion Effect of Superfine Extinguishing Agent Dispersed by Different Energetic Gas Generating Agents [J]. Explosive Materials, 2008, 37(6):4-7.

[9] Hu Song-tao. Design on A Trip Igniter Used in Dry Powder Fire Extinguishing Bomb [J]. Initiators \& Pyrotechnics, 2014(6):13-15.

[10] Yang Jie. Composition Design of Aerosol Generating Agent and Fire Extinguishing Mechanism [J]. Chinese Journal of Explosives \& Propellants, 2003, 26(4):84-86. 